\title{
Traumatic pneumothorax: is a chest drain always necessary?
}

Graham Johnson

\begin{abstract}
Objective-To examine the management of traumatic pneumothorax in a department where some of these injuries do not receive chest drains.

Methods-A retrospective study of the management of traumatic pneumothorax was performed on a unit where historically many of these injuries have been treated conservatively.

Results-54 pneumothoraces in a three year period were identified. Of these, 29 injuries $(54 \cdot 7 \%)$ were initially managed without drainage. Two patients subsequently had chest drains inserted as a result of asymptomatic radiological enlargement of the pneumothorax while inpatients. No patients deteriorated clinically during conservative treatment.

Conclusions-Chest drain insertion for small or moderate sized traumatic pneumothoraces, in the absence of other significant injuries or the need for intermittent positive pressure ventilation (IPPV), may be unnecessary.

( f Accid Emerg Med 1996;13:173-174)
\end{abstract}

Key terms: traumatic pneumothorax; accident and emergency department; treatment

The insertion of a chest drain is widely recommended as the gold standard and mainstay of treatment for traumatic pneumothorax. ${ }^{12}$ The advanced trauma life support (ATLS) course recognises the options of observation or aspiration but dismisses these as being risky because of the possibility of tension pneumothorax. ${ }^{3}$ However, the insertion of a chest drain is not an innocuous procedure, with a complication rate of $9.1 \%$ in pneumothorax as a result of blunt trauma ${ }^{4}$ and 18 potential complications, some of which may be associated with significant morbidity and even mortality. ${ }^{3}$

In this study I examine the management of traumatic pneumothorax in a department where some of these injuries do not receive chest drains.

\footnotetext{
Accident and Emergency Department Derriford Hospital Plymouth PL6 8DH G Johnson

Correspondence to: G S Johnson FRCS Consultant in Emergency Medicine, St James's University Hospital Leeds LS9 7TF.
}

\section{Methods}

Patient discharged from the accident and emergency (A\&E) department at Derriford Hospital Plymouth with a diagnosis of traumatic pneumothorax were identified by a search of the departments' computerised database for the period of 1 January 1991 to 31 December 1993.

The hospital notes and $A \& E$ records were retrieved and information abstracted con- cerning the mechanism of injury, the presence of other injuries, and the method of treatment of traumatic pneumothorax and its outcome. Associated injuries were defined as significant if they required an operative procedure for treatment or scored greater than 1 on the abbreviated injury scale. ${ }^{5}$

As the study was retrospective and radiographic technique variable, attempts to quantify the size of the pneumothoraces were limited. All the records contained a subjective assessment of the size of the pneumothorax by the doctor managing the patient and these were noted.

\section{Results}

Fifty four pneumothoraces in 53 patients were found. In one case the hospital notes could not be traced and the patient was therefore excluded.

The mechanisms of injury and methods of treatment are shown in the table. Initial treatment involved insertion of an intercostal drain in 24 cases. The majority of patients injured in road traffic accidents were in this group and significant associated injuries were frequent. In 29 pneumothoraces, initial management was observation only, either as an inpatient or as an outpatient. Chest drain insertion was subsequently undertaken in two patients because of asymptomatic radiological enlargement of the pneumothorax six hours after admission. In neither of these patients was there any clinical deterioration before insertion of the chest drain. The remaining pneumothoraces resolved without intervention. The road traffic accident group were underrepresented and associated injuries were few and minor. In most cases the traumatic pneumothorax was an isolated injury.

All conservatively treated pneumothoraces were described as "small", "minimal", or "moderate". All those described as "large", "complete", or "total" were treated initially with chest drains.

\begin{tabular}{|c|c|c|c|}
\hline & $\begin{array}{l}\text { Conservative } \\
\text { management }\end{array}$ & $\begin{array}{l}\text { Chest tube } \\
\text { insertion }\end{array}$ & Total \\
\hline $\begin{array}{l}\text { Blunt } \\
\text { Penetrating }\end{array}$ & $\begin{array}{r}27 \\
2\end{array}$ & $\begin{array}{r}22 \\
2\end{array}$ & $\begin{array}{r}49 \\
4\end{array}$ \\
\hline $\begin{array}{l}\text { Falls } \\
\text { RTA } \\
\text { Assault } \\
\text { Sport } \\
\text { Industrial }\end{array}$ & $\begin{array}{r}14 \\
5 \\
5 \\
5 \\
0\end{array}$ & $\begin{array}{r}5 \\
11 \\
4 \\
3 \\
1\end{array}$ & $\begin{array}{r}19 \\
16 \\
9 \\
8 \\
1\end{array}$ \\
\hline Other significant injuries & 4 & 13 & 17 \\
\hline Total & 29 & 24 & 53 \\
\hline
\end{tabular}

Hod


In six cases, presentation to the department was delayed by more than 24 hours and in three of these cases observation was by daily clinical review and radiography as an outpatient. All late presentations of traumatic pneumothorax resolved without intervention.

\section{Discussion}

The results suggests that some traumatic pneumothoraces will resolve spontaneously when left untreated. Although often part of a multisystem injury, in this series most traumatic pneumothoraces were isolated injuries, and management of the pneumothorax was not influenced by the presence of other injuries or the need for IPPV. Under these conditions a chest drain was often not required.

Previous attempts to reduce the hospital admission and morbidity associated with chest tube insertion have included outpatient management with chest tube and Heimlich flutter valve $^{6}$ and inpatient and outpatient use of catheter aspiration for traumatic pneumothorax. ${ }^{78}$ However, conservative management of traumatic pneumothoraces is rarely reported. In a large South African series of predominantly penetrating injuries to the chest, ${ }^{9}$ traumatic pneumothoraces were initially managed conservatively if there was less than $20 \%$ reduction in lung volume. In all 333 patients $(41.4 \%)$ were initially treated conservatively. In $10 \%$ of these cases a chest drain was subsequently inserted because of enlargement of the pneumothorax.

There are no prospective randomised controlled trials comparing the conservative management of all traumatic pneumothoraces with the insertion of chest drains. Occult pneumothoraces, defined as those recognised by abdominal computerised tomographic (CT) scanning but not detected on routine screening chest $x$ rays, occur in $2-6 \%{ }^{10}$ of patients undergoing CT scanning for blunt abdominal trauma. A recent randomised prospective study of the management of these injuries ${ }^{11}$ has shown that they may be safely managed conservatively in the absence of the use of IPPV. However, patients with an occult pneumothorax who also received IPPV had a high rate of progression of the size of their pneumo- thoraces, with three out of 21 developing tension pneumothorax.

The insertion of a chest drain is therefore not an essential part of the treatment of traumatic pneumothorax. Patients presenting within 24 hours of injury should be admitted for analgesia, regular monitoring of vital signs, and oximetry. A repeat chest $x$ ray should be performed after six hours and the insertion of a chest drain reconsidered if the pneumothorax is increasing in size. However, drainage remains mandatory when IPPV is required or when the degree of collapse is producing respiratory compromise.

When the pneumothorax is the patient's only significant injury and there is no respiratory compromise, most of these injuries will resolve spontaneously without exposing the patient to the risks associated with the use of a chest drain. A prospective randomised trial of chest drainage versus conservative management in traumatic pneumothorax is required to define the treatment criteria accurately, specifically the pneumothorax size.

I would like to thank Mr Ian Stewart, Dr Henry Guly, and $\mathrm{Mr}$ Iain Grant for allowing me to study their patients and for their support in this project.

1 Trunkey DD, Lewis FR. Chest trauma. Surg Clin North Am 1980;60:1541-9.

2 Nealon TF. Trauma to the chest. In: Gibbon JH, Sabiston DC, Spencer FC, eds. Surgery of the Chest, vol 1, 5th ed. Philadelphia: WB Saunders:1990:170-1.

3 Committee on Trauma, American College of Surgeons. Advanced trauma life support. Chicago: American College of Surgeons, 1993:123.

4 Daly RC, Mucha P, Pairolero PC, Farnell MB. The risk of percutaneous chest tube thoracostomy for blunt thoracic trauma. Ann Emerg Med 1985;14:865-70.

5 Association for the Advancement of Automotive Medicine The abbreviated injury scale. Des Plaines: Association for the Advancement of Automotive Medicine, 1990.

6 Page A, Cossette R, Dontigny L. Spontaneous pneumothorax: out-patient management with intercostal tube drainage. Can Med Assoc F 1975;112:707-9.

7 Mukherjee D, Lyon J. A simple treatment for pneumothorax. Surg Gynecol Obstet 1983;156:499-500.

8 Obeid FN, Shapiro MJ, Richardson HH, Horst HM, Bivins BA. Catheter aspiration for simple pneumothorax (CASP) in the outpatient management of simple traumatic pneumothorax. $\mathcal{F}$ Trauma $1985 ; 25: 882-5$.

9 Knatic pneumothorax. F Trauma IW. Traumatic pneumothorax: a scheme for rapid patient turnover. Injury 1990; thorax: a

10 Garramone RR, Jacobs LM, Sahdev P. An objective measure to measure and manage occult pneumothorax. measure to measure and manage occult
Surg Gynecol Obstet 1991;173:257-61.

11 Enderson BL, Abdalla R, Frame SB, Casey MT, Gould H, Maull KI. Tube thoracostomy for occult pneumothorax: a prospective randomised study of its use. $\mathcal{F}$ Trauma 1993;35:726-30. 